\title{
MEASURING VALUE AT RISK USING GARCH MODEL - EVIDENCE FROM THE CRYPTOCURRENCY MARKET
}

\author{
Cosmos Obeng \\ Tomas Bata University, Faculty of Management and Economics, Zlin, Czech Republic \\ Email: obeng@utb.cz
}

Received: 7 July 2021. Revision received: 23 August 2021. Accepted: 20 September 2021

\begin{abstract}
There is a growing interest in the activities of the crypto market by various stakeholders. These stakeholders generally include investors, entrepreneurs, governments, fund managers, climate activists, institutional managers, employees with surplus funds, and crypto miners. This study aims to investigate the accuracy of the GARCH models for measuring and estimating Valueat-risk (VaR) using the Cryptocurrency index for future investment and managerial decision making. Because of this, the present study uses the top 30 Cryptocurrencies index in terms of Market capitalization excluding stable coins to determine the best GARCH models. Many entrepreneurs, institutional managers, fund managers, and other stakeholders have recently included cryptocurrency in their investment portfolio because of the increase in transactions and high returns growth in the global financial market with its associated high returns and volatility. Information communication technology has paved the way for such activities in the global markets. The daily data frequency was applied because of the availability of the data. The empirical analysis has been carried out for the period from January 2017 to December 2020 for a total of 1461observation. The returns volatility is estimated using SGARCH and EGARCH models. The findings evidenced that, using both normal distribution and Student t distribution, EGARCH provides a better measure and estimate than SGARCH concerning high persistence and volatility. Against this background, the present study also examined Backtesting to estimate Value at Risk. Interestingly, the findings of the available study would provide industry players, practitioners, entrepreneurs, and investors the maximum edge on how to use or measure such variables against others to make investment decisions. Also, the findings would subsequently contribute more insight into academia on the study area.
\end{abstract}

KEYWORDS: Volatility, Value-at-Risk, Cryptocurrency Market, GARCH-Model

JEL CLASSIFICATION: G17, L26, K 22.

Reference: Obeng, C., (2021). Measuring Value at Risk using GARCH model - evidence from the cryptocurrency market. International Journal of Entrepreneurial Knowledge, 9(2), 63-84. doi: 10.37335/ijek.v9i2.133

\section{INTRODUCTION}

With the development of digital finance and digital contracts and the increasing trend of the growth of popularity, cryptocurrencies have gained massive attention in current financial markets. This new asset provides various diverse opinions of the risk and returns. In contrast to the traditional asset markets, the cryptocurrency market is an emerging one and consists of a large market capitalization. Bitcoin, the most notable digital cryptocurrency, was created by Satoshi Nakambo in 2009 after the financial crisis. As a first known Cryptocurrency, most of the literature has been interested in its volatility (Bouoiyour \& Selmi,2016; Blau, 2017; Conrad et al., 2018; Al-Khazali et al. 2018 and safe-haven and hedging abilities of cryptocurrencies (Bouri et al., 2020(b) Shahzad et al.,2019; Klein et al., 2018). According to coinmarketcap.com, as of $25^{\text {th }}$ of February 2021, there were over 8000 different types of cryptocurrencies on the crypto market with a total market capitalization of over 1.55 Trillion Dollars (www. coinmarketcap.com). According to Chaim \& Laurini (2019), the volatility of cryptocurrencies was higher than traditional assets, which signals higher returns and higher risks.

Several studies have analyzed and explained the dynamics of the volatility of cryptocurrencies. Katsiampa (2017) postulates that in explaining the volatility dynamics of Bitcoin, the Autoregressive-Component Generalized Autoregressive Conditional Heteroscedasticity (AR-CGACRH) model provides the most 


\section{INTERNATIONAL JOURNAL OF ENTREPRENEURIAL KNOWLEDGE}

Issue 9, volume 2, ISSN 2336-2960 (Online)

www.ijek.org

suitable GARCH model approach. However, Tiwari et al. (2019) concluded that the distribution volatility-based model provides a better explanation of the volatility of Bitcoin and Litecoins, relative to the several other GARCH volatility models available for modeling the returns of Bitcoin and Litecoins. Even though VaR model estimation came into existence about two decades ago, academic literature on VaR estimation is limited on the Cryptocurrency markets. This article compares the predictive ability of GARCH models in the backdrop of VaR forecasts. However, scanty research has been conducted on volatility and its Value at risk on the Crypto market, which paves the way for such a comprehensive study to reveal the market's dynamism. The research would adopt the top 30 cryptocurrencies index to analyze their impacts on the market. This research paper aims to fill the gap of using the top 30 cryptocurrencies to better measure volatility by using Value at Risk on the Crypto Market. The study would be useful to academia since empirical evidence on the measurement of Cryptocurrencies would be revealed through the findings. Furthermore, it would be beneficial to industry players in policy formulation and strategies as this will attract both new and existing customers via Value at risk analysis on the Crypto market. This paper is arranged in sections as follows: literature review, methodology, findings/results, discussions, and conclusion.

\section{LITERATURE REVIEW}

Most research papers focus on GARCH model in forecasting the Value at risk of Bitcoin, except for a few which consider the combination of bitcoin with popular cryptocurrencies, stocks, and world currencies (Delfin-Vidal et al (2016) Ardia et al(2019) Liu et al (2020) Trucios (2019). The following authors used GARCH family and basic benchmark model in financial research for VaR estimation on the crypto market (e.g. Bouoiyou \& Selmi (2014); Nieto, M. R., \& Ruiz, E. (2016). Bouoiyou \& Selmi (2016), Bouri et al (2019a) Delfin-Vidal et al (2016), Katsiampa (2017), Peng et al (2018, Ardia \& Hoogerheide (2014).

For example, Peng et al (2018) compare model performance using SVRGARCH, EGARCH and GJRGARCH, assuming symmetric and asymmetric by employing Gaussian and student t distribution. It was concluded that support vector regression GARCH followed by GJRGARCH was best to forecast volatility on the bitcoin market. Dilek Teker \&Suat Teker (2020) tested using ARCH, GARCH, TGARCH and EGARCH to explain bitcoin return volatility movement. The empirical results shows that GARCH $(1,1)$ fit best to explain bitcoin returns volatility movement for the sampling data used. Katsiampa (2017) also estimated the volatility of Bitcoin returns, and the empirical results showed that AR (1) -CGARCH was best to estimate volatility returns. Liu et al also estimated Bitcoin returns volatility by employing normal reciprocal inverse Gaussian (NRIG) with normal distribution and student t error under GARCH. In conclusion, GARCH with Student $t$ distribution outperforms better than the remaining models.

Other studies were extended to include other financial assets. Dyhrberg (2016)-estimate the volatility of Bitcoin, Gold and US Dollars using GARCH and asymmetric EGARCH models and concluded both models behave the same way and can best be used for hedging. The results as revealed by the studies of both Bouoiyour \& Selmi (2015) and Dyhrberg (2016) showed many similarities of Bitcoin volatility patterns and demonstrated that negative news seems to greatly affect volatility in contrast to good news. Notwithstanding, Dyhrberg (2016), using asymmetric GARCH conducted a study that revealed that bitcoin could be very useful in the management of risks for risk-averse investors who predominantly act on negative news on the market. Bouoiyour and Selmi (2019) analyzed the volatility of the price of Bitcoin by applying the different GARCH models. They divided the data period into two periods (Dec 2010June 2015 and January 2015-June 2015). In their analysis, their first results depicted that adopting an estimated Threshold GARCH model pointed evidence towards persistent volatility whiles the second results revealed that an Exponential GARCH model was fitted and had less persistent volatility. 


\section{INTERNATIONAL JOURNAL OF ENTREPRENEURIAL KNOWLEDGE}

Issue 9, volume 2, ISSN 2336-2960 (Online)

www.ijek.org

Furthermore, they postulate that negative news influences Bitcoin volatility in the market compared to that of good news.

In addition, other research work was extended to include other crypto coins. (Chen, S. et al., 2016; Chu at al.,2017; Yousaf \& Ali ,2020; Liu at al.,2020; Tan at al.,2020). For instance, Chu at al (2017) employed twelve different GARCH type models to better model volatility by using data from seven most famous cryptocurrencies namely: Bitcoin, Dash, Dogecoin, Litecoin, Maidsafecoin, Monero, Ripple excluding Ether which also has a high market capitalization. They concluded that IGARCH and GJRGARCH was the best fit to model volatility on the crypto market. Naimy et al (2021) also uses six major cryptocurrencies: Bitcoin, Litecoin, Monero, Dash, Dogecoin and Ripple. Based on the results, it was concluded IGARCH is the best model for Monero while GJR -GARCH model was best fit to model in -sample volatility of the remaining cryptocurrencies. On the other hand, CGARCH and TGARCH is an optimal model for out of sample interval for all the assets used.

Chen, S. et al (2016) used GARCH type to model volatility from a family of CRI index family using data from 2014-2016. He concluded that TGARCH $(1,1)$ model was the best first based on information criterion (AIC and BIC).

Although several procedures have been implemented to forecast daily volatility and VaR in cryptocurrency data, little attention has been paid to huge sum of the total crypto market. The aim of this paper is to provide GARCH-type measurement of Value at Risk of top 30 Cryptocurrencies in terms of market capitalization except for stable coin. Overall, this research distinguish itself from other empirical studies by covering large sums of cryptocurrencies in terms of market capitalization to find the best model to measure market risk on the crypto market.

\section{AIM AND DATA METHODOLOGY}

The aim of this study is to investigate the accuracy of the GARCH models for measuring and estimating Value-at risk (VaR) using Cryptocurrency index.As already indicated in the data set (closing stock price) of CCI that is the top 30 Cryptocurrencies in terms of market capitalization listed www.cci30.com) excluding stable coin was selected and analyzed using descriptive statistics. This forms 85 percent of the total crypto market capitalization. The data is secondary data. As a result, descriptive statistics of the data including mean, standard deviation, maximum and minimum return, median, and standard error of the mean were adopted. To estimate the extent of the volatility of the return's series, the GARCH type models are accurately used. Moreover, to identify if the returns series is stationary, Augmented DickeyFuller Test is adopted. The Ljung Box test and the Arch LM test are equally used to assess the impact of autocorrelation and ARCH effects respectively. Invalidating the non-normality assumption, the JacqueBera normality test is conducted.

\subsection{GARCH volatility models}

GARCH is an acronym for generalized autoregressive conditional heteroscedasticity. Heteroscedasticity is representative of time-varying variance(volatility). The extent to which the observations depend on the immediate past is represented as Conditional, and the infusion of the past observation into the present using the feedback mechanism is autoregressive. Therefore, the GARCH model is a mechanism for explaining future variances with the inclusion of past variances. Explicitly, as a time-series technique, GARCH facilitates the adoption of a model to examine the serial reliance of volatility. GARCH models give an accurate description for heteroscedastic time series relative to other time-series models. Bollerslev, in 1986 developed an extension of Engle's (1982) original ARCH volatility modeling technique called GARCH. He developed GARCH to give a model which is based on fewer assumptions to ease 
INTERNATIONAL JOURNAL OF ENTREPRENEURIAL KNOWLEDGE

Issue 9, volume 2, ISSN 2336-2960 (Online)

www.ijek.org

computations. Subsequently and in furtherance, Nelson (1991) developed a model using logarithm to indicate and assess the conditional variability that is present in the unknown variable under analysis. This, he called exponential GARCH (EGARCH). As a result of Nelson's EGARCH, Glosten et al., (1993) developed a derivative model which recognizes the asymmetry of a shock to a variable, GJR-GARCH. Christoffersen et al., (2004) began practicalizing the GARCH model in the capital market and have become extensively and widely applied to emerging and existing areas including, asset allocation and option pricing, portfolio management, risk management among others.

\subsection{GARCH models}

\subsubsection{Statistics}

An in-depth representation of the statistics is given, where $\mathrm{X}$ denotes a discrete-valued stochastic variable, $\mathrm{k}$ is the summation index, and 0xpk is the probability of $\mathrm{X}$ taking the value $\mathrm{k}$. The population mean, representing the first moment is given as

$$
E(X)=\sum_{\mathrm{k}} \mathrm{X}_{\mathrm{k}} x p k=\mu
$$

The second non-central moment is then represented with

$$
E\left(X^{2}\right)=\sum_{\mathrm{k}} \mathrm{X}^{2} x p k-\mu^{2}
$$

Generally, non-central moments are given as

$$
\mathrm{r}=1,2,3 \ldots \ldots \ldots
$$

Skewness is represented with

$$
\frac{E\left((X-\mu)^{3}\right)}{(\operatorname{Var}(X))^{3 / 2}}
$$

It is assumed that the normal distribution has a skewness of zero. However, a skewness with a positive result is more likely to have values far exceeding the mean Value compared with how far it is below the mean Value.

Kurtosis is represented as

$$
\frac{\left((X-\mu)^{4}\right)}{\operatorname{Var}(X))^{2}}
$$

\subsubsection{ENGLE ARCH Effects}

ARCH Engle test was computed to determine if the residuals are heteroscedastic, and the squared residuals are auto-correlated. A lot of tests can be used to fit the square of the residual but in this study, in other to ensure that the test fits the linear regression for the residuals and to assess the significance of the fitted model, the Lagrange Multiplier is applied. The null hypothesis is that the residuals are homoscedastic, meaning the squared residuals are a result of the white noise. 
INTERNATIONAL JOURNAL OF ENTREPRENEURIAL KNOWLEDGE

Issue 9, volume 2, ISSN 2336-2960 (Online)

www.ijek.org

\subsubsection{Lagrange Multiplier (LM) Test}

Normally, the F-Statistics for testing $\alpha_{i}=0,(i=1, \ldots \ldots m$ in linear regression is equal to this test $z_{t}^{2}=\alpha_{0}+\alpha_{1} z_{t-1}^{2}+\ldots \ldots \alpha_{m} z_{t-m}^{2}+\varepsilon_{t}, \mathrm{t}=\mathrm{m}+1, \ldots . \mathrm{T}$

Where $\varepsilon_{-} \mathrm{t}$ defines the error term, $\mathrm{m}$ defines a pre-determined positive integer and $\mathrm{T}$ denotes the size of the sample. The test statistic is given by

$F=\frac{\left(\left(S S R_{0}-S S R_{01}\right) / m\right.}{S S R_{1} /\left(T-2_{m}-1\right)}$

Where $S S R_{0}=\sum_{t=m+1}^{T}\left(z^{2}-œ\right),\left(z^{2}-œ\right), œ=(1 / T) \sum_{t=1}^{T} Z_{T}^{2}$ and $S S R_{1}=\sum_{t=m+1}^{T} \varepsilon_{t}^{2}, \varepsilon_{t} \quad$ is denotes the least squared residuals of the initial linear regressions. $F$, represented as chi-squared distribution with $\mathrm{m}$ degrees of freedom under the null hypothesis, is thus distributed asymptotically. Where $\mathrm{F}$ is greater than the corresponding critical Value of the chi-squared distribution with $\mathrm{m}$-degrees of freedom for an identified level of significance $(\alpha)$, the null hypothesis is rejected. Alternatively, I rejected the null hypothesis where the significance level, $\alpha$ is more than the p-value of F.

\subsubsection{Models of changing variance}

The GARCH type models can capture most of the features of financial time series data, including thicktailed returns and volatility grouping. Again, this model facilitates explaining heteroscedasticity. The Generalized Autoregressive Conditional Heteroscedasticity (GARCH) model first developed by Bollerslev (1986) is an add-on to the ARCH model proposed in 1982 by Engel. The GARCH model overcomes some of the limitations of the ARCH model such as the principle of parsimony.

\subsubsection{GARCH (p, q) model}

Consider the log return of an asset at time t given by

$r_{t}=\mu_{t}+z_{t}$

Where represents the conditional mean of $z_{t}$ and is the mean-corrected log return and is denoted by

$z_{t}=\sigma_{t} \varepsilon_{t}$

Where $\varepsilon_{t}$ is an independent and identically distributed random variable having a zero mean 0 and a unit variance independent of past realization of $z_{t-1}$ and

$\sigma_{t}^{2}=\alpha_{0}+\alpha_{1} z_{t-p}^{2}+\phi_{q} \sigma_{t-q}^{2} z_{t}$

Stated differently

$\sigma_{t}^{2}=\alpha_{0}+\sum_{i=1}^{\mathrm{p}} z_{t-1}^{2}+\sum_{j=1}^{q} \phi_{t-j}^{2}$

where $\alpha_{0}, \alpha_{i}(i=1,2 \ldots, \mathrm{p}) \phi_{j}(j=1,2 \ldots, \mathrm{q})$ and give the parameters of the model.To ensure, $\phi_{j}(j=1,2 \ldots, \mathrm{q})$ it is assume and $\alpha_{0}>0, \alpha_{i} \geq 0 \phi_{j} \geq 0$. 
INTERNATIONAL JOURNAL OF ENTREPRENEURIAL KNOWLEDGE

Issue 9, volume 2, ISSN 2336-2960 (Online)

www.ijek.org

The $z_{t}$ model for with property in $(3(\mathrm{j}))$ is known as the Generalized Autoregressive Conditional Heteroscedasticity (GARCH) model of order (p, q) and represented as GARCH (p, q). The conditional variance of the error process is, in addition to the squares of past errors, the past conditional variances. The distribution of the innovation is taken to be standard normal (Gaussian), standardized student- $t$ distribution, or the generalized error distribution (GED).

The GARCH model extends the ARCH model by introducing $q$ new parameters for the volatility equation. When $q=0$ in equation $(3(\mathrm{j}))$ it reduces to an ARCH (p) model. The parameters are known as the ARCH parameter and, called the GARCH parameter. It could be quite misleading to conclude that the conditional variance follows an ARMA $(\mathrm{p}, \mathrm{q})$ model with $\mathrm{p}$ being the AR order and $\mathrm{q}$ the MA order. In an ARMA process, the related error is a white noise procedure that agrees almost exactly to the onestep-ahead forecast error.

Let then

by substituting into equation $(3(1))=$

$z_{t}^{2}-\alpha_{t}=\alpha_{0}+\sum_{i=1}^{\mathrm{p}} \alpha\left(z_{t-1}^{2}-\alpha_{t-1}\right)+\sum_{j=1}^{\mathrm{q}} \phi_{j} z_{t-1}^{2}$

$z_{t}^{2}=\alpha_{0}+\sum_{i=1}^{\mathrm{r}}\left(\alpha_{i}+\phi_{i}\right) z_{t-1}^{2}-\sum_{j=1}^{\mathrm{p}} \alpha_{j} \alpha_{t-1}^{2}+\alpha_{t}$

where $r=\max (p, q)$, for for and for

Thus, the GARCH (p, q) model in equations (3(i)) and (3(j)) implies that follows an

$\operatorname{ARMA}(r, q)$ model where $r=\max (p, q)$.

where $\mathrm{r}=\max (\mathrm{p}, \mathrm{q}), \alpha_{i}=0$ for $\alpha_{i}=0$ for $i>p$ and $\phi_{i}=0$ for $i>q$

Thus, the GARCH $(p, q)$ model in equations (3(i)) and (3(j)) implies that $z_{t}^{2}$ follows an $\operatorname{ARMA}(r, q)$ model where $\mathrm{r}=\max (\mathrm{p}, \mathrm{q})$.

\subsubsection{GAARCH (p,q) model estimation}

This section deals with the extent of maximum likelihood estimation of the GARCH $(p, q)$ parameter. After identifying the orders $p$ and $q$, the initial variances and the squared returns, the parameters $\alpha_{0}, \alpha_{1}, \ldots, \alpha_{p}, \phi_{1}, \ldots, \phi_{q}$, of the model can be estimated using the maximum likelihood estimation method. The estimates of the parameters are obtained through maximizing the conditional likelihood function given by.

$$
L\left(\alpha_{0}, \alpha, \phi \mid \mathrm{z}_{\mathrm{t}}, \sigma_{t}^{2}\right)=\prod_{\mathrm{t}=1}^{\mathrm{T}}\left(\frac{1}{2 \pi \sigma_{\mathrm{t}}^{2}}\right)^{1 / 2} \exp \left(\frac{-z_{t}^{2}}{2 \sigma_{t}^{2}}\right)
$$

or the conditional log-likelihood function

$$
\operatorname{In} L\left(\alpha_{0}, \alpha, \phi \mid \mathrm{z}_{\mathrm{t},} \sigma_{t}^{2}\right)=\sum_{\mathrm{t}=1}^{\mathrm{T}} \frac{1}{2}\left(-\operatorname{In}(2 \pi)-\operatorname{In}\left(\sigma_{t}^{2}\right)-\frac{z_{t}^{2}}{\sigma_{t}^{2}}\right)
$$

\subsubsection{Forecasting with GARCH (p, q) model}

Considering the GARCH model specified in equations $(3(\mathrm{l}))$ and $(3(\mathrm{~m}))$, the $k$-step ahead volatility forecast can be obtained using similar methods as those used in an ARMA model. Taking a forecast 
INTERNATIONAL JOURNAL OF ENTREPRENEURIAL KNOWLEDGE

Issue 9, volume 2, ISSN 2336-2960 (Online)

www.ijek.org

origin of $h$ and substituting the estimates of $\boldsymbol{\alpha}(\boldsymbol{i}=\mathbf{1}, . \mathrm{p})$ and $\phi_{j}(j=1, \ldots, \mathrm{q})$ with their actual values and assuming $z_{h}^{2}, \ldots, z_{h+1-\rho}^{2}, \sigma_{h}^{2}, \ldots ., \sigma_{h+1-q}^{1}$ are known. Then the $k$-step ahead volatility forecast is given by

$$
\begin{aligned}
& z_{h}^{2}(k)=\mathrm{E}\left(z_{h+k}^{2} \mid \mathrm{z}_{\mathrm{h}}\right) \\
=\alpha_{0} & +\sum_{i=1}^{p}\left(\alpha_{i}+\phi_{i}\right) \mathrm{E}\left(z_{h+k-1}^{2} \mid \mathrm{z}_{\mathrm{h}}\right)-\sum_{j=1}^{q} \phi_{j} \mathrm{E}\left(\alpha_{h+k-j} \mid \mathrm{z}_{\mathrm{h}}\right)+\alpha_{h} \\
= & \sigma_{\mathrm{h}}^{2}(k)
\end{aligned}
$$

\subsubsection{EGARCH (p, q) model}

The EGARCH model was developed to make possible the incorporation of the impact of asymmetry between positive and negative shocks on the conditional variance of the future observations. Again, as pointed out by Nelson Ans Cao (1992), the model enjoys no restrictions on the associated parameters. An asymmetric function of lagged disturbances is the conditional variance, in the EGARCH model. The EGARCH model is thus represented as

$\varepsilon_{i}=\xi_{\mathrm{i}} h_{i} 1 / 2$

$\operatorname{In}\left(h_{t}\right)=\alpha_{0}+\frac{1+b_{1} B+\ldots .+b_{q-1} B^{q-1}}{1-\alpha_{1} B+\ldots+\alpha_{P} B^{P}} g\left(\varepsilon_{t-1}\right)$

where,

$$
g\left(\varepsilon_{t-1}\right)= \begin{cases}(\theta+\gamma) \varepsilon_{\mathrm{t}}-\gamma \mathrm{E}\left(\left|\varepsilon_{t}\right|\right), & \text { if } \varepsilon_{t} \geq 0 \\ ((\theta-\gamma)) \varepsilon_{t}-\gamma \mathrm{E}\left(\left|\varepsilon_{\mathrm{t}}\right|\right) & \text { if } \varepsilon_{t}<0\end{cases}
$$

$\mathrm{B}$ is the backshift (or lag) operator such that

$\operatorname{Bg}\left(\varepsilon_{t}\right)=\mathrm{g}\left(\varepsilon_{\mathrm{t}-1}\right)$

A variance depicting the EGARCH model can also be by specifying the logarithm of the conditional variance. This results in an exponential leverage effect, rather than one that is quadratic, and the forecasts of the conditional variance are assumed to be non-negative. Karanasos \& Kim (2003) have presented an expansive analysis of the moments structure of the ARMA-EGARCH model.

\subsection{Value-at-Risk (VaR)}

Credit risk, model risk, liquidity risk, market risk, and operational risk are a few examples of risk facing financial institutions. Value-at-Risk is one way of evaluating market risk. VaR is defined as the maximum possible loss, given a confidence level, over a given period. The $\mathrm{VaR}$ of a portfolio at $\alpha[0 \leq \alpha \leq 1]$ the confidence level is the smallest number $\ell$ such that the probability of the worst possible loss on the portfolio $(\omega)$ is more than $\ell$ is at most $(1-\alpha)$. Mathematically $\operatorname{VaR}_{\alpha}=\inf \{\ell \in R: P(\omega>\ell) \leq 1-\alpha\}$ - VaR is a simple term that connotes the quantile of the loss distribution.

\subsubsection{VaR under GARCH type models}


INTERNATIONAL JOURNAL OF ENTREPRENEURIAL KNOWLEDGE

Issue 9, volume 2, ISSN 2336-2960 (Online)

www.ijek.org

Consider a general regression model for the log return of an asset at time $t$ denoted as, which can be written as $r_{t}=\theta_{0}+\sum_{i=1}^{m} \theta_{i} r_{t-1}-\sum_{j=1}^{s} \beta_{\mathrm{j}} z_{t-j}+z_{t}$

The mean and volatility equations are given by equations (3.3a) and (3.3b) respectively. Assuming all parameters are known, then the above-stated equations are useful in obtaining a 1-step ahead forecast of the conditional mean $\left(\hat{\mu}_{t}\right)$ and variance $\left(\hat{\sigma}_{t}^{2}\right)$ of $r_{t}$

$\hat{\mu}(1)=\theta_{0}+\sum_{i=1}^{m} \theta_{i} r_{t+1-i}-\sum_{j=1}^{s} \beta_{j} z_{t+1-j} 3.3 \mathrm{a}, \quad \hat{\sigma}_{t}^{2}=\alpha_{0}+\sum_{i=1}^{p} \alpha_{i} z_{t+1-i}^{2}+\sum_{j=1}^{q} \phi_{\mathrm{j}} \sigma_{t+1-j}^{2} 3.3 \mathrm{~b}$

The innovation $\left(\varepsilon_{t}\right)$ is assumed to have a Gaussian distribution, standard student -t distribution or Generalizes Error Distribution (GED). For the study, we assume $\varepsilon_{t}$ follows Gaussian distribution or standard student -t distribution.

If $\varepsilon_{t}$ follows Gaussian distribution, then the distribution of $r_{t+1}$ conditional on information available at the time $t N(\hat{\mu}(1)), \hat{\sigma}(1))$ is. Quantiles of this conditional distribution can be obtained for a 1-step ahead VaR calculation. The quantile, in this case, will be $\hat{\mu}(1)+N_{\alpha} \hat{\sigma}_{t}(1)$. Where $N_{\alpha}$ are the appropriate standards normal deviate?

If $\varepsilon_{t}$ follows a student $\mathrm{t}$ distribution with $\mathrm{v}$ degree of freedom, then its associated quantile used to calculate a 1 -step ahead $\mathrm{VaR}$ is $\hat{\mu}(1)+t_{v}^{*}(p) \hat{\sigma}_{t}(1)$.

Where $\boldsymbol{t}_{v}^{*}(p)$ is the ${ }^{\text {th }}$ quantile of a student t distribution with v degree of freedom.

\subsection{Model selection criteria}

There are various bases of information relevant in determining the order of a model. The Akaike Information Criteria (AIC) by Akaike (1974), Bayesian Information Criterion (BIC) by Schwartz (1978), and Hannan-Quinn (HQ) by Hannan \& Quinn (1979) are some of the bases available. Every model selection basis aims to ensure the balance of the measure of goodness of fit and the parsimonious specification of the model. The AIC, BIC, HQ, etc values of competing models are used in ranking the models. The model with the lowest Value is chosen. In case two or more competing models have similar values, then the model with the least number of parameters is chosen. AIC and BIC were used in the research paper.

\subsubsection{Akaike Information Criteria (AIC) and Bayesian Information Criterion}

The AIC can be used for in-sample and out-sample comparison forecasting the performance of a model akin to the BIC.Akaike information criterion (AIC) and Bayesian information criterion (BIC) are examples of standard model evaluation criteria applicable in the comparison of the performance of different models. These criteria penalize the decrease in the degree of freedom when more variables are added. For the ARIMA model it is computed as follow:

$\mathrm{AIC}=\mathrm{T}^{\prime} \log \left(\sigma^{2}\right)+2(p+q+1)$

$\mathrm{BIC}=\mathrm{T}^{\prime} \log \left(\sigma^{2}\right)+(p+q+1) \log T^{\prime}$

Where $T^{\prime}$ is the number of observations used for the estimation of parameters and $\sigma^{2}$ denotes the mean square error.

\subsubsection{Model Adequacy Checks}


INTERNATIONAL JOURNAL OF ENTREPRENEURIAL KNOWLEDGE

Issue 9, volume 2, ISSN 2336-2960 (Online)

www.ijek.org

Any fitted model should be checked for model adequacy. An adequately fitted model has the residuals of the series behaving like white noise (Tsay, 2005). The ACF and Ljung-Box statistics of the residuals are applied in assessing the closeness of the residuals to white noise. Specifically, to check the adequacy of the mean equation and that of standardized squared residuals used to check the adequacy of the volatility equation, the Ljung-Box statistics of the standardized residuals are very relevant. Also, assessing the validity of the assumption of distribution, skewness, kurtosis, and Q-Q plot of the standardized residuals are used. A fitted model that is insufficient is refined. For instance, where there are estimated coefficients that are statistically insignificant, then the model should be simplified by removing the insignificant parameters. The model in some instances should be extended to take care of additional serial correlations where ACF of the residuals depicts as such.

\subsubsection{Model Validation}

To mimic actual industry practice, it was necessary to segregate the data set into two. The initialization set (in-sample) and the verification set (out-of-sample). Model parameters were estimated with the initialization set while the verification set was used to validate the model. It is necessary to know how well a model forecasts, so we use the verification set to compare with the forecasted values

\subsubsection{Assessment of Forecast Accuracy}

Several measures for assessing the predictive accuracy of GARCH- type models have been proposed by researchers. Amongst them, the Mean square error (MSE) and Mean absolute error (MAE) are used.

The MSE is defined as

MSE $=\sum_{\mathrm{t}=1}^{\mathrm{T}} \frac{\left(\mathrm{x}_{\mathrm{t}}^{2}-\hat{\sigma}_{t}^{2}\right)^{2}}{T}$ Meanwhile, the Mean absolute error (MAE) developed is given as

$\mathrm{MAE}=\sum_{\mathrm{t}=1}^{\mathrm{T}} \frac{\left|\mathrm{x}_{\mathrm{t}}^{2}-\hat{\sigma}_{t}^{2}\right|}{T}$

Where $x_{t}^{2}$ is the squared time series observation and $\hat{\sigma}_{t}^{2}, \mathrm{t}=1 \ldots, \mathrm{T}$ is the estimated conditional variance from the fitted model.

\subsection{Back-testing under GARCH}

There exists a situation where the number of times returns, in absolute Value, exceed the forecasted VaR. This frequency of deviation is called the Failure rate. Back-testing is a statistical procedure that examines whether the failure rate corresponds with the specified confidence level. If the model is accurately given, the failure rate is expected to equalize the specified VaR level. For example, if at $99 \%$ confidence level daily $\mathrm{VaR}$ estimates are computed for 100 trading days, then we would expect on average $1 \mathrm{VaR}$ violation during this period. These types of statistical tests are known as the test of unconditional coverage. This study uses the Kupiec test to back-test its VaR models.

\subsection{Kupiec Test}

Kupiec (1995) proposed the proportion of failures test (POF). This test checks whether the observed number of VaR exceedance as compared to the expected number is statistically reasonable. Simply put, the POF test is used to assess the extent or frequency of exceedances that is appropriate for a given confidence level. 
INTERNATIONAL JOURNAL OF ENTREPRENEURIAL KNOWLEDGE

Issue 9, volume 2, ISSN 2336-2960 (Online)

www.ijek.org

Let the frequency of exceedances be $x$ and frequency of observations be $N$. Then the failure rate is given by $x / N$. It follows a binomial distribution since an observation results in either a VaR exceedance or not. Now assuming model accuracy, the observed failure rate

^ $\rho=\mathrm{x} / \mathrm{N}$ should be an unbiased estimate of the expected failure rate specified

by the confidence level $p$. In essence, the POF test just determines if ${ }^{\wedge}$ it deviates greatly from

The null hypothesis under the POF test is

$$
H_{0}: \rho=\rho=\mathrm{x} / \mathrm{N}
$$

\section{EMPIRICAL ANALYSIS AND DISCUSSION}

This part detailed the empirical analysis and discussion of the results obtained. It is divided into the following sections: Data description, preliminary analysis, in-sample, and out-of-sample volatility measurement, $\mathrm{VaR}$ model estimation, and forecasting and diagnostic test to check the volatility model.

\subsection{Summary Statistics and Data Description}

The data consist of the daily closing prices of Cryptocurrencies Index 30 on the crypto market from January 2017 to December 2020 covering a total period of 4 years. The daily simple returns of Cryptocurrencies Index 30 closing prices with total observations of 1461 were calculated. Cryptocurrencies Index 30 involves the 30 largest cryptocurrencies by market capitalization, excluding stable coins. Cryptocurrencies Index 30 is chosen because of the availability of data for the top 30 Cryptocurrencies on the Crypto Market. It involves the daily and long-term movement of the blockchain sector. The descriptive statistics for CCI daily returns are shown in the table below.

Table 1 Descriptive Statistics of the daily returns

\begin{tabular}{|l|l|}
\hline Descriptive Statistics of the daily returns \\
\hline Mean & 4278.7 \\
\hline Median & 3672.4 \\
\hline Minimum & 276.35 \\
\hline Maximum & 20797 \\
\hline Standard deviation & 2947.2 \\
\hline Skewness & 2.1070 \\
\hline Excess Kurtosis & 6.1412 \\
\hline C.V & 0.68882 \\
\hline Jarque-Bera & 925.25 \\
\hline
\end{tabular}

(Source: Author's calculations)

As an empirical study of 4 years Crypto Currencies Index 30 stock daily closing prices from January 2017 to $31^{\text {st }}$ December 2020, we calculated the daily return as:

Daily simple returns: $R i=\frac{\mathrm{P}_{\mathrm{t}}}{\mathrm{P}_{\mathrm{t}-}}-1$ 
INTERNATIONAL JOURNAL OF ENTREPRENEURIAL KNOWLEDGE

Issue 9, volume 2, ISSN 2336-2960 (Online)

www.ijek.org

Daily logarithmic returns: $R i=\operatorname{In}\left(\frac{\mathrm{P}_{\mathrm{i}}}{\mathrm{P}_{\mathrm{t}-1}}\right)=\operatorname{In}\left(1+\mathrm{R}_{\mathrm{i}}\right)$

Also plotted the daily simple returns for the whole period of January 2017-December 2020. The result from the summary descriptive statistics shows a large positive returns and slight positive skewness. Moreover, the standard deviation generated from the sample data exhibited is large from the selected crypto index as compared to normal traditional currencies, Naimy \& Hayek (2018).

Figure 1 Time series of Cryptocurrencies Index 30 daily simple returns 2017-2020

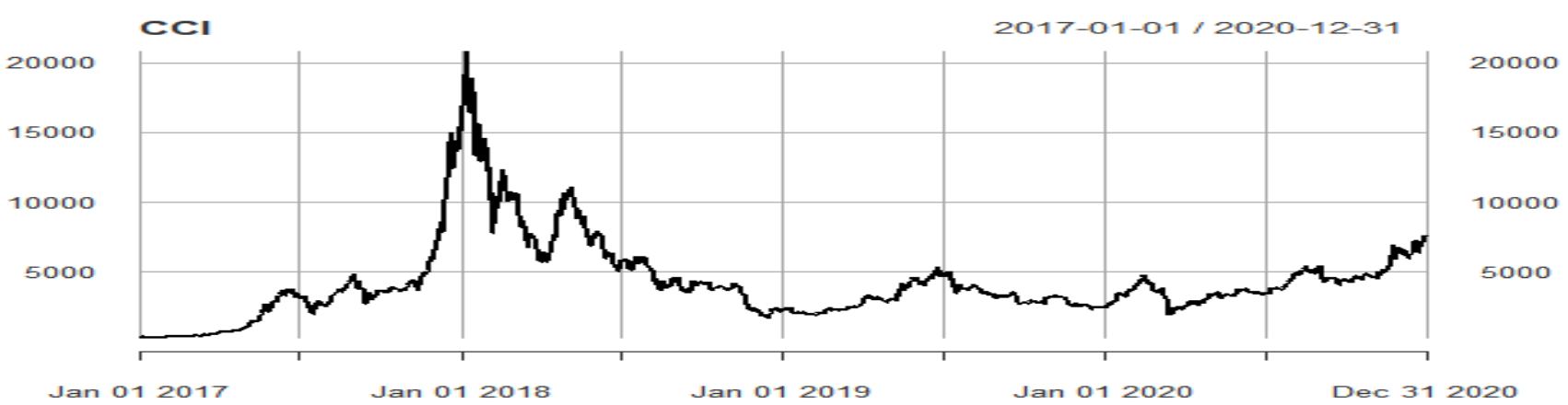

(Source: author's calculation)

The plot Figure 1 shows the daily simple returns of cryptocurrencies index from 2017-2020. There was upward swing in January 2018 and followed by a persistent plummet in in the succeeding year January 2019 and later slightly increase in from 2020.

Figure 2 Plot of Daily compounded returns

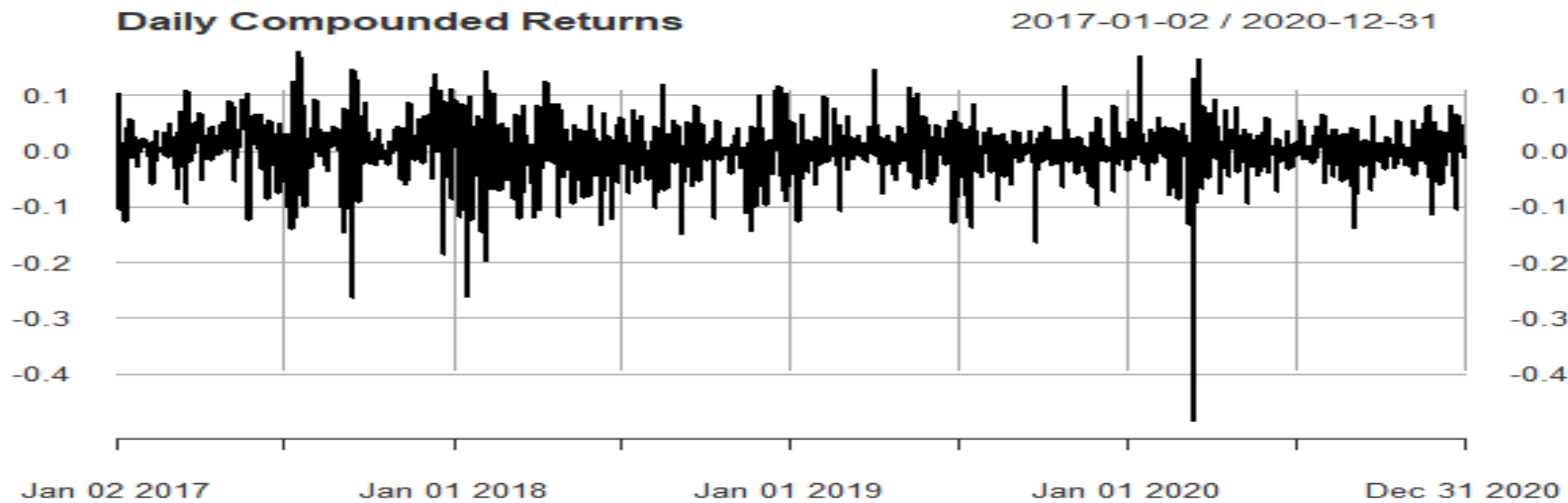

(Sources: Author's computation)

The daily log returns were calculated. The time series plot figure 2 above shows non-trending but somehow stationary daily returns. It can be seen that high volatile days are followed by swing downward volatile days and unstable predictions in the rate of volatility.

The Graph shows the daily compounded returns of CCI30, it can be inferred that the returns were very volatile in the first quarter of 2020. The previous swing in downward volatility was recorded in early 2018 and the last quarter of 2017. The high volatility in the first quarter of 2020 can be attributed to the global corona virus pandemics with its associated lockdown and financial uncertainty. 
INTERNATIONAL JOURNAL OF ENTREPRENEURIAL KNOWLEDGE

Issue 9, volume 2, ISSN 2336-2960 (Online)

www.ijek.org

\section{$\mathrm{ACF}$ and PACF}

To test for serial correlation in the simple return series, the Autocorrelation Function (ACF) plot and the Partial Autocorrelation Function (PACF) plot of the return's series were obtained.

Figure 3 ACF of daily returns

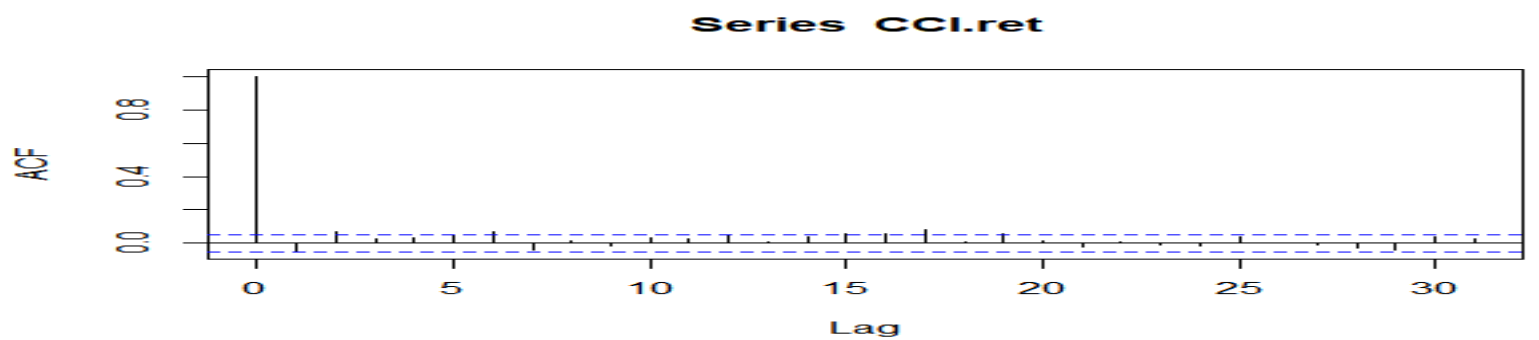

(Source: Author's calculations)

Figure 4 PACF of daily returns

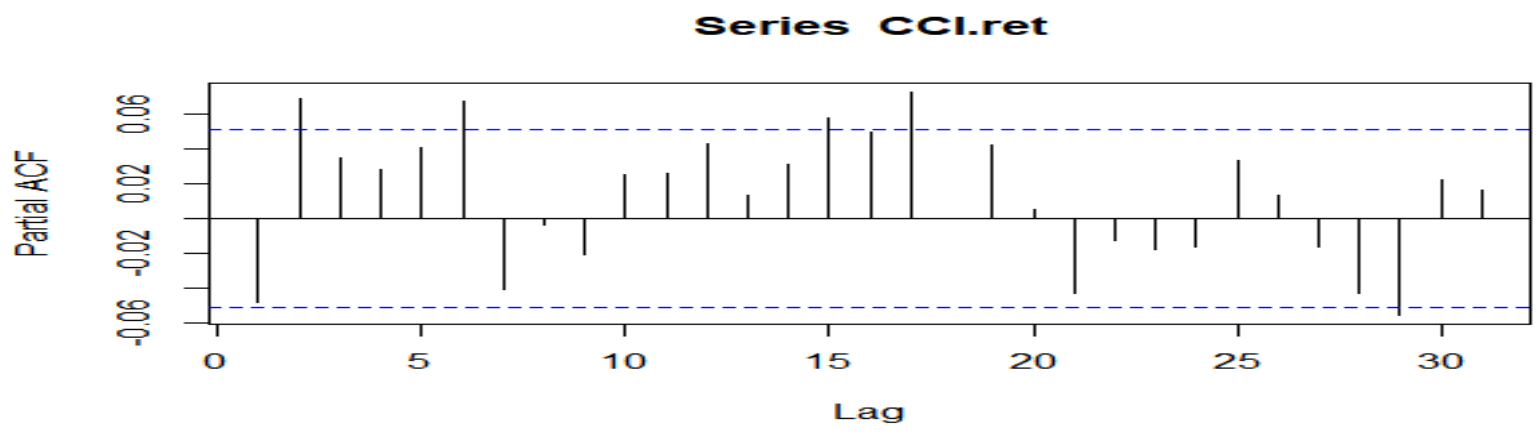

(Source: Author's calculations)

The ACF plot and PACF that is Figure 3 and 4 illustrates several spikes indicating that there is some significant serial correlation in the returns. Their corresponding Ljung-Box statistics confirm that there is a serial dependence of $5 \%$ significance level among the series returns. The Ljung-Box Statistics at lag (10) while the ACF and PACF plots of CCI30 are shown Figure 5 below.

Figure 5 Standard residuals, ACF of residuals, p values for Ljung-Box statistic 
INTERNATIONAL JOURNAL OF ENTREPRENEURIAL KNOWLEDGE

Issue 9, volume 2, ISSN 2336-2960 (Online)

www.ijek.org

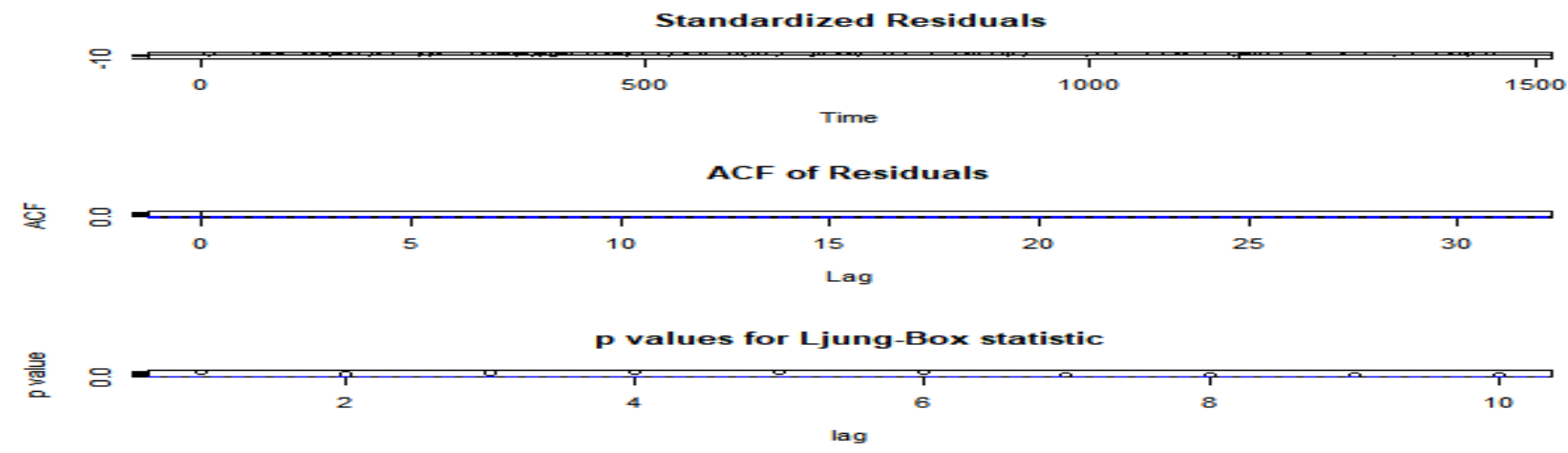

(Source: Author's calculations)

\section{A Test for ARCH Effects}

A test (ARCH effects) for Autoregressive Conditional Heteroscedasticity was done to confirm the presence of heteroscedasticity (changing variance over time) in the residuals of the fitted models' equation made. The Lagrange Multiplier (LM) test proposed by ENGLE (1982) could have been used. The results of the selected lags are shown. The null hypothesis that there are no ARCH effects was rejected at a $5 \%$ level of significance for CCI 30 closing prices at all lags. To check the GARCH model, the residuals of ARIMA need to have the ARCH effect for randomness. The Ljung-Box test is performed on the first 10 lags of the squared residuals of the best ARIMA model under the null hypothesis of no ARCH effects. Box-Ljung test data: best_ARIMA $\$$ residuals^2 X-squared $=51.071, \mathrm{df}=10, \mathrm{p}$-value $=1.695 \mathrm{e}-076$

\section{Table 2 Best ARIMA chosen}

\begin{tabular}{|l|l|l|}
\hline \multicolumn{2}{|l|}{ confint(best_ARIMA) } \\
\hline & $2.50 \%$ & $97.50 \%$ \\
\hline ar1 & 0.88166172 & 1.0042775 \\
\hline ma1 & -1.07252874 & -0.9146045 \\
\hline ma2 & 0.03300108 & 0.1333636 \\
\hline
\end{tabular}

(Source: Author's calculations)

The results above Table 2 show the confidence interval of the best ARIMA model.

If the p-value of the Ljung-Box test is smaller than the 5\% level of significance, then there exists the ARCH effect, hence we do not reject the null. Since the returns series for satisfying the properties of GARCH types of volatility models, and estimation of models of Generalized Autoregressive Heteroscedasticity (GARCH) type models are made.

\section{Model Estimation}

Since all the desirable properties have been satisfied, a determination of the order of the model is made. The ACF and PACF graphs of the series help to determine the Moving Averages (MA) order and Autoregressive (AR) order respectively. Based on the Information Criteria, the best ARMA is chosen for CCI. However, to get the best fit model our models were built around information criteria with the lowest AIC values, therefore an ARMA $(1,2)$ is suggested for CCI. The best model is selected based on the AIC 
INTERNATIONAL JOURNAL OF ENTREPRENEURIAL KNOWLEDGE

Issue 9, volume 2, ISSN 2336-2960 (Online)

www.ijek.org

criterion. Based on the information criteria - the Akaike Information Criteria in the table below, it is estimated that the best model for modeling the logarithmic returns series for CCI is ARMA $(1,2)$.

Best model: ARIMA $(1,0,2)$ with zero mean

Table 3 Criteria for ARIMA (p,q) Selection based on AIC

\begin{tabular}{|l|l|l|l|l|ll|}
\hline ARIMA $(2,0,2)$ & With non-zero mean & -4826.926 & & & $\begin{array}{l}\text { Normal } \\
\text { distribution }\end{array}$ & $\begin{array}{l}\text { Student-t } \\
\text { Distribution }\end{array}$ \\
\hline ARIMA $(0,0,0)$ & With non-zero mean & -4819.197 & SGARCH $(1,1)$ & AIC & -3.4360 & -3.6577 \\
\hline ARIMA $(1,0,0)$ & With non-zero mean & -4819.808 & & BIC & -3.4106 & -3.6287 \\
\hline ARIMA $(0,0,1)$ & With non-zero mean & -4820.182 & EGARCH(1,1) & AIC & -3.4478 & -3.6638 \\
\hline ARIMA $(0,0,0)$ & with zero mean & -4818.007 & & BIC & -3.4189 & -3.6212 \\
\hline ARIMA $(1,0,2)$ & With non-zero mean & -4830.117 & SGARCH(2,1) & AIC & -3.4347 & -3.6563 \\
\hline ARIMA $(0,0,2)$ & With non-zero mean & -4825.706 & & BIC & -3.4057 & -3.6237 \\
\hline ARIMA $(1,0,1)$ & With non-zero mean & -4822.618 & EGARCH(2,1) & AIC & -3.4499 & -3.6638 \\
\hline ARIMA $(1,0,3)$ & With non-zero mean & -4829.609 & & BIC & -3.4101 & -3.6239 \\
\hline ARIMA $(0,0,3)$ & With non-zero mean & -4824.455 & & & & \\
\hline ARIMA $(2,0,1)$ & With non-zero mean & -4827.947 & SGARCH(1,2) & AIC & -3.4346 & -3.6574 \\
\hline ARIMA $(2,0,3)$ & With non-zero mean & Inf & & BIC & -3.4056 & -3.6248 \\
\hline ARIMA $(1,0,2)$ & with zero mean & -4830.8327 & EGARCH(1,2) & AIC & -3.4465 & -3.6635 \\
\hline ARIMA $(0,0,2)$ & with zero mean & -4824.627 & & BIC & -3.4139 & 3.6272 \\
\hline ARIMA $(1,0,1)$ & with zero mean & -4821.375 & SGARCH(2,2) & AIC & -3.4344 & -3.6560 \\
\hline ARIMA $(2,0,2)$ & with zero mean & -4827.502 & & BIC & -3.4018 & -3.6198 \\
\hline ARIMA $(1,0,3)$ & with zero mean & -4830.339 & EGARCH(2,2) & AIC & $-\mathbf{3 . 4 6 1 8}$ & $\mathbf{- 3 . 6 6 2 5}$ \\
\hline ARIMA $(0,0,1)$ & with zero mean & -4818.707 & & BIC & $-\mathbf{3 . 4 2 1 9}$ & $\mathbf{- 3 . 6 1 9 1}$ \\
\hline ARIMA $(0,0,3)$ & with zero mean & -4823.478 & & & & \\
\hline ARIMA $(2,0,1)$ & with zero mean & -4828.51 & & & & \\
\hline ARIMA $(2,0,3)$ & with zero mean & -4826.408 & & & & \\
\hline
\end{tabular}

(Source: Author's calculations)

A look at the plot Figure 2 to 4 , and table 2 provide for the regular information criterion, residuals, the autocorrelation function of the residuals, and the p-values of the Portmanteau test for all lags. It exhibits non-zero partial autocorrelation until lag 1, implying that a AR 1 process of MA order 2 is appropriate.

\section{GARCH Model Selection}

From Table 3 EGARCH (p, q) model with normally distributed innovations EGARCH $(2,2)$ is chosen for CCI with a Normal distribution whiles EGARCH $(2,2)$ is chosen if innovations follow a student tdistribution. These models are chosen because they had the lowest AIC and BIC values. Moreover, the best optimal GARCH was selected on ME, RSME and MAE error metrics. Table 4 presents the results of the error measures and information criterion.

Table 4 Coefficients: AIC and BIC Information criterion

\begin{tabular}{|c|c|c|c|c|c|}
\hline & \multicolumn{3}{|c|}{ Coefficients: } & \multicolumn{2}{|c|}{ Training set error measures: } \\
\hline & ar1 & ma1 & $\mathrm{ma} 2$ & $\mathrm{ME}$ & 0.001406016 \\
\hline
\end{tabular}


INTERNATIONAL JOURNAL OF ENTREPRENEURIAL KNOWLEDGE

Issue 9, volume 2, ISSN 2336-2960 (Online)

www.ijek.org

\begin{tabular}{|c|c|c|c|c|c|}
\hline & 0.943 & -0.9936 & 0.0832 & RMSE & 0.04610276 \\
\hline s.e. & 0.0313 & 0.0403 & 0.0256 & MAE & 0.03098929 \\
\hline \multicolumn{4}{|c|}{$\begin{array}{l}\mathrm{BIC}=-4811.97 \operatorname{sigma}^{\wedge} 2 \text { estimated as } 0.00213: \log \\
\text { likelihood }=2420.56\end{array}$} & MPE & $\mathrm{NaN}$ \\
\hline \multirow[t]{3}{*}{$\begin{array}{l}\mathrm{AIC}=- \\
4833.12\end{array}$} & $\begin{array}{l}\mathrm{AICc}=- \\
4833.09\end{array}$ & $\begin{array}{l}\text { BIC }=- \\
4811.97\end{array}$ & & MAPE & Inf \\
\hline & & & & MASE & 0.6708931 \\
\hline & & & & ACF1 & -0.003647207 \\
\hline
\end{tabular}

(Source: Author's calculations)

The above summary shows coefficients, information criterion, and the training error measures (the mean error, root mean squared error, mean absolute error, mean percentage error, mean absolute percentage error, and the mean absolute scaled error). These measures showed the accuracy of the forecast of the model compared to the other models.

Figure 6 Forecasts from ARIMA

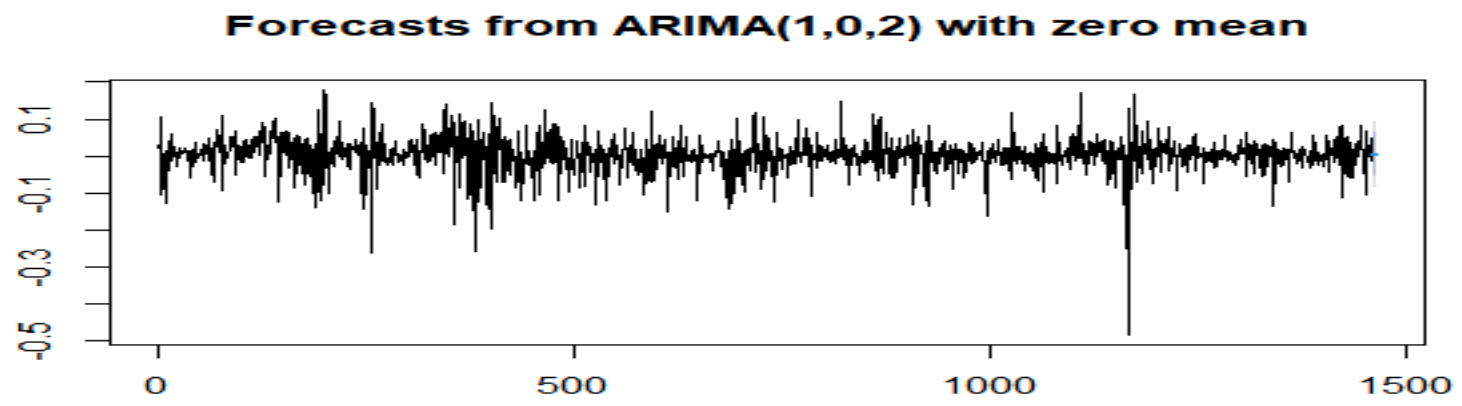

(Source: Author's calculations)

The plot Figure 6 shows the forecast for ARIMA $(1,2)$ with zero mean. This shows the tenacious volatility in the chosen model.

\section{Parameter estimates for each model}

Having selected the mean and variance equation for both returns and before turning to the out-of-sample analysis, it is worth first looking at some parameter estimates obtained by fitting the models on the data. Table 6 and Table 7 reports full sample estimation results over the period January 2017 to December 2020 for a total of 1461 daily observations.

Table 6 Parameter estimate of selected model with Student t Distribution In- Sampling Estimation 
INTERNATIONAL JOURNAL OF ENTREPRENEURIAL KNOWLEDGE

Issue 9, volume 2, ISSN 2336-2960 (Online)

www.ijek.org

\begin{tabular}{|l|l|l|l|l|l|l|l|l||} 
& $\begin{array}{l}\text { SGARCH } \\
\mathbf{( 1 , 1 )}\end{array}$ & $\begin{array}{l}\text { EGARCH } \\
\mathbf{( 1 , 1 )}\end{array}$ & $\begin{array}{l}\text { SGARCH } \\
\mathbf{( 1 , 2 )}\end{array}$ & $\begin{array}{l}\text { EGARCH } \\
\mathbf{( 1 , 2 )}\end{array}$ & $\begin{array}{l}\text { SGARCH } \\
\mathbf{( 2 , 1 )}\end{array}$ & $\begin{array}{l}\text { EGARCH } \\
\mathbf{( 2 , 1 )}\end{array}$ & $\begin{array}{l}\text { SGARCH } \\
\mathbf{( 2 , 2 )}\end{array}$ & $\begin{array}{l}\text { EGARCH } \\
\mathbf{( 2 , 2 )}\end{array}$ \\
\hline $\mathrm{Mu}$ & 0.013173 & 0.012561 & 0.013245 & 0.012735 & 0.013175 & 0.012614 & 0.013254 & 0.126252 \\
\hline ar1 & 0.994969 & 0.994767 & 0.994917 & 0.994567 & 0.994971 & 0.99465 & 0.99492 & 0.99464 \\
\hline ma1 & -1.062905 & -1.0611403 & -1.060811 & -1.05866 & -1.062907 & -1.05477 & -1.060847 & -1.054917 \\
\hline ma2 & 0.087046 & 0.085893 & 0.085342 & 0.084238 & 0.087044 & 0.079786 & 0.085388 & 0.079971 \\
\hline Omega & 0.000159 & -0.302148 & 0.00197 & -0.361982 & 0.000159 & -0.261751 & 0.000197 & -0.303495 \\
\hline alpha1 & 0.20421 & 0.00136 & 0.26129 & -0.003254 & 0.204226 & -0.090875 & 0.261427 & -0.08933 \\
\hline alpha2 & & & & & 0.000001 & 0.104457 & 0 & 0.103182 \\
\hline beta1 & 0.794787 & 0.950011 & 0.45582 & 0.629299 & 0.794771 & 0.956654 & 0.45585 & 0.801596 \\
\hline beta2 & & & 0.281889 & 0.280828 & & & 0.281723 & 0.148121 \\
\hline gamma1 & & 0.295281 & & 0.362351 & & 0.331965 & & 0.340456 \\
\hline gamma2 & & & & & & -0.054644 & & -0.019113 \\
\hline shape & 2.897699 & 2.924126 & 2.919992 & 2.924982 & 2.897828 & 2.948383 & 2.919199 & 2.941520 \\
\hline
\end{tabular}

(Source: Author's calculations)

Table 7 Parameter estimate of selected model with Normal distribution

Backtesting

\begin{tabular}{|c|c|c|c|c|c|c|c|c|}
\hline & \multicolumn{8}{|c|}{ PARAMETER ESTIMATE OF SELECTED MODEL } \\
\hline & \multicolumn{8}{|c|}{ Normal Distribution } \\
\hline & $\begin{array}{l}\text { SGARC } \\
\text { H }(1,1)\end{array}$ & $\begin{array}{l}\text { EGARCH } \\
(1,1)\end{array}$ & $\begin{array}{l}\text { SGARCH } \\
(1,2)\end{array}$ & $\begin{array}{l}\text { EGARCH } \\
(1,2)\end{array}$ & $\begin{array}{l}\text { SGARCH } \\
(2,1)\end{array}$ & $\begin{array}{l}\text { EGARCH } \\
(2,1)\end{array}$ & $\begin{array}{l}\text { SGARCH } \\
(2,2)\end{array}$ & EGARCH $(2,2)$ \\
\hline $\mathrm{Mu}$ & 0.005755 & 0.03874 & 0.00577 & 0.003945 & 0.005364 & 0.003769 & 0.002781 & 0.004115 \\
\hline ar1 & 0.995644 & 0.987175 & 0.99567 & 0.987861 & 0.995137 & 0.467719 & 0.115249 & 0.99192 \\
\hline $\operatorname{ar} 2$ & & & & & & 0.510755 & & \\
\hline ar3 & & & & & & & & \\
\hline ma1 & -1.02365 & -1.017095 & -1.023777 & -1.016893 & -1.022568 & -0.514529 & -0.135602 & -1.034311 \\
\hline $\mathrm{ma} 2$ & 0.036178 & 0.042482 & 0.036277 & 0.04135 & 0.035774 & -0.445007 & 0.094029 & 0.054415 \\
\hline Omega & 0.00015 & -0.450742 & 0.00015 & -0.483958 & 0.000154 & -0.443732 & 0.000155 & -0.954024 \\
\hline alpha1 & 0.145788 & -0.055148 & 0.145834 & -0.060318 & 0.129696 & -0.143755 & 0.140079 & -0.08823 \\
\hline alpha2 & & & & & 0.017310 & 0.099728 & 0.010006 & -0.023882 \\
\hline beta1 & 0.797503 & 0.924608 & 0.797423 & 0.811061 & 0.793625 & 0.925813 & 0.790772 & -0.020877 \\
\hline beta2 & & & 0.000003 & 0.107935 & & & 0 & 0.862372 \\
\hline gamma1 & & 0.233294 & & 0.253455 & & 0.17816 & & 0.13708 \\
\hline gamma2 & & & & & & 0.054108 & & 0.341087 \\
\hline
\end{tabular}

(Source: Author's calculations)

To check the accuracy of the Value at Risk Kupiec conditional coverage test was performed on the outof sample performance model. Backtesting is a useful test for checking the model performance. Backtest in a risk model compares the estimated VaR with the actual return over the period. Backlist these bases on the out-sample performance model since there are different distributions of residuals for every model. Accordingly, AIC criteria in our determination, for example, it has an ARMA $(1,2)$-SGARCH $(1,1)$ model with a normal distribution of residuals, ARMA1(1,2)-EGARCH (1,1) model. In the backtesting, a 
INTERNATIONAL JOURNAL OF ENTREPRENEURIAL KNOWLEDGE

Issue 9, volume 2, ISSN 2336-2960 (Online)

www.ijek.org

forecasting methodology is provided in Table 8-10 where we compare actual VaR forecasts with the SGARCH and EGARCH models. VaR Forecast for competing SGARCH $(1,1)$ and EGARCH $(1,1)$ Models under Normal distribution and Student-t distribution. It can be inferred that, there is a great similarity in all the forecast results.

Figure 7 VaR Forecast for competing SGARCH $(1,1)$ and EGARCH $(1,1)$ at $1 \%$ VaR Limit
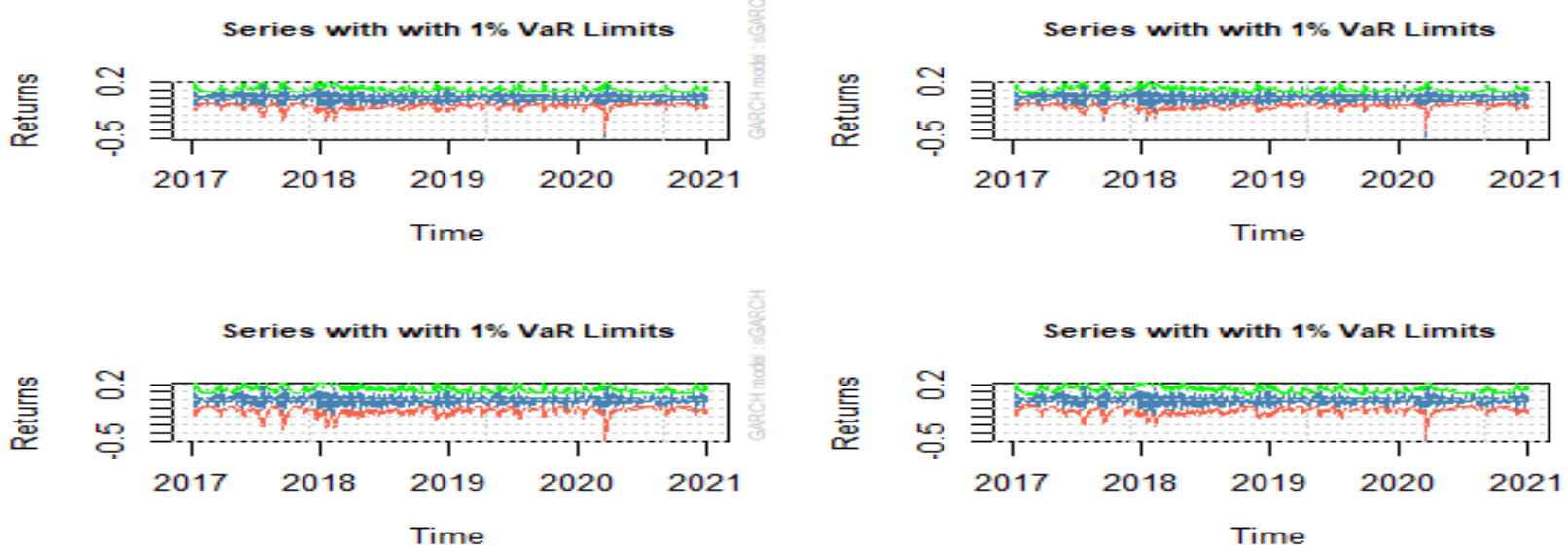

(Source: Author's calculations)

VaR Forecast for competing SGARCH $(1,1)$ and EGARCH $(1,1)$ Models under Normal distribution and Student- $t$ distribution. The results below synthesize the results of VaR backtesting including the unconditional coverage test (Kupiec LR.uc) and the conditional coverage test (ChristoffersenLR.cc) at a $1 \%$ alpha level.

Table 8 Christofferson's test

\begin{tabular}{|ll|l|l|l||}
\hline & & \multicolumn{3}{|l||}{ INDEPENDENCE TEST (CHRISTOFFERSEN'S TEST) } \\
\hline alpha-0.01 & & TEST STATISTICS & CRITICAL VALUE & TEST OUTCOME \\
\hline $\begin{array}{l}\text { SGARCH } \\
\text { NORM }\end{array}$ & & 0.865 & $9.21(0.649)$ & \\
\hline $\begin{array}{l}\text { EGARCH } \\
\text { NORM }\end{array}$ & $(1,1)$ & 0.865 & $9.21(0.649)$ & REJECT NULL -NO \\
\hline \hline
\end{tabular}

(Source: Author's calculations)

Table 9 Kupiec conditional coverage test

\begin{tabular}{|c|c|c|c|c|}
\hline & Kupiec condit & tional coveras & e test & $\begin{array}{l}\text { Number of actual } \\
\text { VaR Exceedance }\end{array}$ \\
\hline alpha-0.01 & \begin{tabular}{|l} 
TEST \\
STATISTICS
\end{tabular} & \begin{tabular}{|l} 
CRITICAL \\
VALUE
\end{tabular} & TEST OUTCOME & \\
\hline \begin{tabular}{|ll} 
GARCH & $(1,1)$ \\
NORM & \\
\end{tabular} & 0.783 & $6.635(0.376)$ & REJECT NULL -NO & 1 \\
\hline \begin{tabular}{||ll} 
EGARCH \\
NORM
\end{tabular} & 0.783 & $6.635(0.376)$ & REJECT NULL -NO & 1 \\
\hline
\end{tabular}

(Source: Author's calculations) 
INTERNATIONAL JOURNAL OF ENTREPRENEURIAL KNOWLEDGE

Issue 9, volume 2, ISSN 2336-2960 (Online)

www.ijek.org

Figure 8 Forecast series with unconditional Sigma
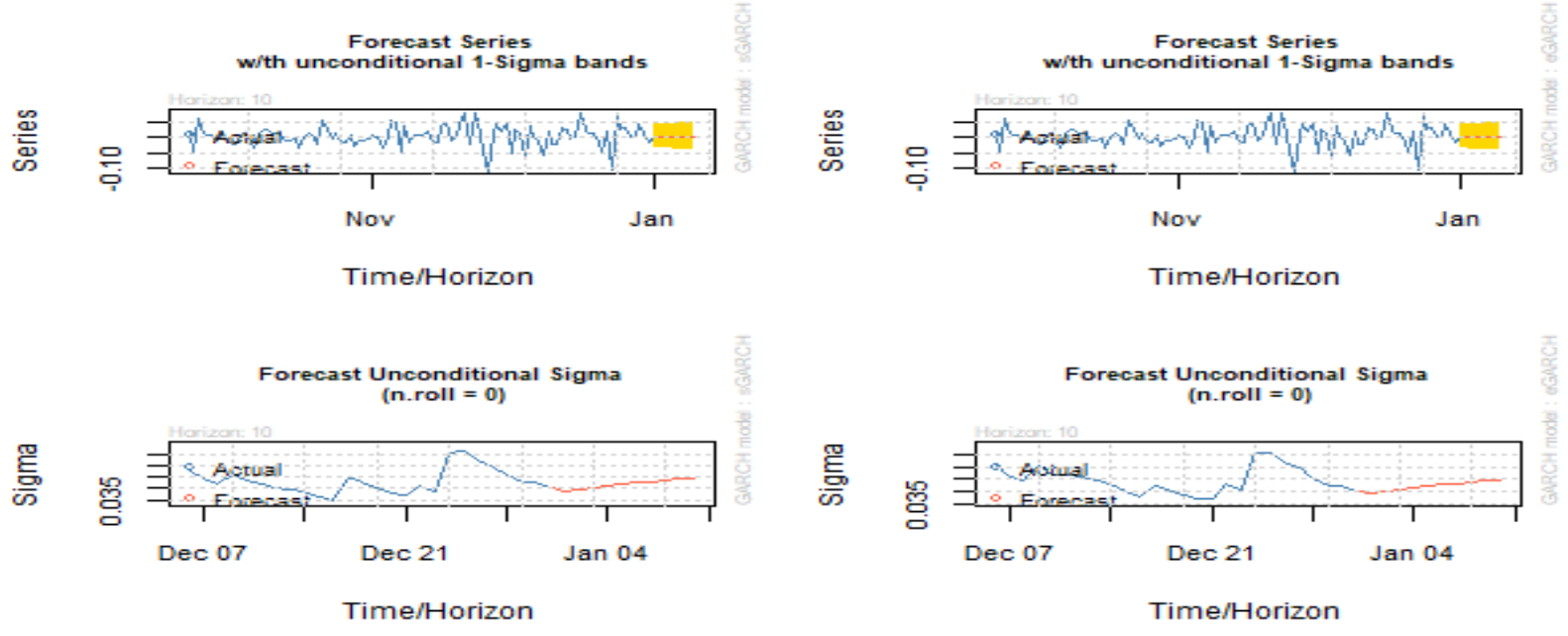

(Source: Author's calculations)

From the visual confirmation (Figure 8) of the Times series and Sigma prediction of ARMA(1,2)$\operatorname{GARCH}(1,1)$ and ARMA(1,2)-EGARCH(1,1), it shows that ARMA(1,1)-SGARCH $(1,1)$ is more volatile by the forecast. The finding of this research shows that the Crypto market asymmetric models perform than the symmetric models. Thus, the asymmetric models provide a better indication of predicting how long a volatility spike will remain elevated or rather model the path of spike back down to long-run mean level. Due to the fact all econometric models rely on past values predicting current values, they can envisage the initial volatility spike up.

\section{DISCUSSION}

The result of Table 6 and Table 7 shows the various EGARCH model with student $t$ distribution confirm that positive returns have a negligible effect in increasing volatility (alpha1) while negative returns have a very large and significant effect (gamma1 and gamma2). The results above are consistent with Bouoiyour \& Semi (2016),(Baur \&Dimplf,2018) and Bouri et al (2019), suggesting that investors respond, in contrast to, positive news, to bad news that has negative returns in the market, as depicted with the results using GARCH family model. On the other hand, for SGARCH $(1,1)$ having student $t$ distribution, it is observed that the estimate of alpha1 $=0.20421$ and beta1 $=0.794787$, with their sum almost equal to 1 , which can be concluded that volatility is very persistent and close to being non-stationary. The Value of the intercept, $m u$ shows positive in the mean equation, across all the models below. This indicates that, as perceived, CCI frequently will have a positive return and its Value will, in the long run, increase.

Moreover, from Table 8 and 9, with the given tail probability of $\mathrm{VaR}$, the number of expected exceedances is compared to the number of actual exceedances in Kupiec's unconditional coverage. On the other hand, the unconditional coverage and the independence of the exceedance is a joint test in Christoffersen's test. The two tests have critical values of 6.635 for LR. uc and 9.21 for the LR.cc test. In this case, owing to the critical Value exceeding or being higher than the statistical Value, we do not reject the null hypothesis. From a sample test conducted using, the Kupiec test and the number of actual exceedances ARMA (1,2)-SGARCH $(1,1)$ and ARMA $(1,2)$-EGARCH $(1,1)$ with normal distributions 


\section{INTERNATIONAL JOURNAL OF ENTREPRENEURIAL KNOWLEDGE}

Issue 9, volume 2, ISSN 2336-2960 (Online)

www.ijek.org

both gives similar results, since it gives the least number of actual VaR exceedance, and the exceedance are correct and independent. Therefore, both models can be used in forecasting. Forecasts of future returns and volatility are obtained based on the in-sample parameter estimates. These forecasts are used to get one step ahead of VaR estimates at $99 \%$ risk coverage. Based on the out-of-sample forecasting performance of SGARCH and EGARCH type models, the ARMA $(1,2)-\mathrm{EGARCH}(1,1)$ with normal distribution and Student $t$ model outperforms the other models. This is shown in Table 11, with EGARCH and SGARCH having DAC of 0.5800 and 0.5700 , respectively. The results above confirm Baur \& Dimpfl (2018), which is also in line with empirical results that show that other distributions rather than normal distributions outperform better. Naimy \& Hayek (2018) also suggested that EGARCH can better predict the volatility of Bitcoin.

Table 11 Mean Forecast Performance Measures of the various models

\begin{tabular}{|l|l|l|l|}
\hline & \multicolumn{3}{|l|}{ Mean Forecast Performance Measures } \\
\hline & MSE & MAE & DAC \\
\hline GARCH $(1,1)$ NORM & 0.001183 & 0.025190 & 0.57000 \\
\hline EGARCH $(1,1)$ NORM & 0.001183 & 0.025190 & 0.58000 \\
\hline GARCH $(1,1)$ STUD. T & 0.001181 & 0.02505 & 0.57000 \\
\hline EGARCH $(1,1)$ STD. $t$ & 0.001181 & 0.025050 & 0.58000 \\
\hline
\end{tabular}

(Source: Author's calculations)

\section{CONCLUSION}

This research paper provides several novel findings related to our selected cryptocurrency index. Many previous studies focused on GARCH modeling for only Bitcoin, while some covered top cryptocurrency with the combination of other trading assets on the financial market. Therefore, the research can help investors, entrepreneurs, and other stakeholders make sound financial and investment decisions. The results from the study showed that the volatility models in estimating VaR on the Cryptocurrency Index in terms of the relative performance, the ARMA $(1,2)-S G A R C H$ and EGARCH with normal distribution and student $t$ distribution for both return series move in the similar pattern. Furthermore, EGARCH provides the best model in volatility measurement and estimation. Concerning the asymmetric models, EGARCH with the various distribution, gamma1, and gamma2 coefficients are positive and significant statistically, indicating how volatility responds differently to bad news relative to good news.

Consequently, this suggests that volatility increases strongly when bad news hits the market and returns are negative. The back-test of VaR showed that with most of the models, the observed failure rate was consistent with the expected failure rates. It is important to be aware that the study was limited to the top 30 Cryptocurrencies in terms of Market capitalization. However, the study can be extended to include Autoregressive stochastic Volatility (ARSV) in future studies. In addition, further empirical studies can be widened to include alternative asset classes involving bonds, stocks, and equities in a portfolio with the various asymmetric and symmetric models.

\section{REFERENCES}

Akaike, H. (1974). A new look at the statistical model identification. Automatic Control, IEEE Transactions on, 19(6), 716-723. https://doi.org/10.1109/TAC.1974.1100705 


\section{INTERNATIONAL JOURNAL OF ENTREPRENEURIAL KNOWLEDGE}

Issue 9, volume 2, ISSN 2336-2960 (Online)

www.ijek.org

Andersen, T. Bollerslev, T. Diebold, F., Ebens, H..2001. The distribution of realized stock return volatility. Journal of Financial Economics 61(1), 43-76 https://doi.org/10.1016/S0304405X(01)00055-1

Ardia, D., Bluteau, K., \& Rüede, M. (2019). Regime changes in Bitcoin GARCH volatility dynamics. Finance Research Letters, 29, 266-271. https://doi.org/10.1016/j.frl.2018.08.009

Bao, Y., Lee, T. H., \& Saltoglu, B. (2006). Evaluating the predictive performance of value-at-risk models in emerging markets: a reality check. Journal of Forecasting, 25(2), 101-128. https://doi.org/10.1002/ for.977

Baur, D.G., K. Hong and A.D. Lee (2018). BitCoin: Medium of exchange or speculative assets? Journal of International Financial Markets, Institutions and Money 54: 177-189. https://doi.org/10.1016/j.intfin.2017.12.004

Blau, B. (2017), "Price dynamics and speculative trading in bitcoin", Research in International Business and Finance, Vol. 41 No. C, pp. 493-499. https://doi.org/10.1016/j.ribaf.2017.05.010

Bollerslev, T. (1986). Generalized autoregressive conditional heteroskedasticity. Journal of econometrics, 31(3), 307-327. https:// doi.org/10.1016/0304-4076(86)90063-1

Bouoiyour, J. and Selmi, R. (2015a), "Bitcoin price: is it really that new round of volatility can be on way?", Munich Personel RePEc Archive, July, p. 65580

Bouri, E., Gupta, R., \& Roubaud, D. (2019a). Herding behavior in cryptocurrencies. Finance Research Letters, 29, 216-221. https://doi.org/10.1016/j.frl.2018.07.008.

Bouri, E., Lucey, B., \& Roubaud, D. (2020b). Cryptocurrencies and the downside risk in equity investments. Finance Research Letters, 33, 101211. https://doi.org/10.1016/j.frl.2019.06.009

Bucevska, V. (2013). An Empirical Evaluation of GARCH Models in Value-at-Risk Estimation: Evidence from the Macedonian Stock Exchange. Business Systems Research, 4(1), $49-64$.

Chaim, P., \& Laurini, M. P. (2019). Nonlinear dependence in cryptocurrency markets. The North American Journal of Economics and Finance, 48, 32-47. https://doi.org/10. 1016/j.najef.2019. 01.015.

Chen, S., Chen, C., Härdle, W. K., Lee, T. M., \& Ong, B. (2016). A first econometric analysis of the CRIX family. Available at SSRN 2832099.

Christoffersen, P., \& Pelletier, D. (2004). Backtesting value-at-risk: A duration-based approach. Journal of Financial Econometrics, 2(1), 84-108. https://doi.org/10.1093/jjfinec/nbh004

Chu,J., Chan, S., Nadarajah, S. and J. Osterrieder. (2017). GARCH Modelling of Cryptocurrencies, Journal of Risk and Financial Management, 10(4), 1-15 https://doi.org/10.3390/jrfm10040017

Conrad, C., Custovic, A., \& Ghysels, E. (2018). Long-and short-term cryptocurrency volatility components: A GARCH-MIDAS analysis. Journal of Risk and Financial Management, 11(2), 23. https://doi.org/10.3390/jrfm11020023

Delfin-Vidal, R., \& Romero-Meléndez, G. (2016). The fractal nature of bitcoin: evidence from wavelet power spectra. Trends in mathematical economics, 73-98 DOI: 10.1007/978-3-319-32543-9_5.

Dowd, K. (2007). Measuring market risk: John Wiley \& Sons.

Dyhrberg, A.H., (2016), Bitcoin, gold and the dollar-A GARCH volatility analysis, Finance Res. Lett. 16 85-92. https://doi.org/10.1016/j.frl.2015.10.008.

Engle, R. F. (1982). Autoregressive conditional heteroscedasticity with estimates of the variance of United Kingdom inflation. Econometrica: Journal of the Econometric Society, 987-1007.

Engle RF, Manganelli S. CAViaR: conditional autoregressive Value-at-Risk by regression quantiles. J. Bus. Econ. Stat. 2004; 22:367-81. doi:10.1198/ 073500104000000370

Frey, R., \& McNeil, A. J. (2002). VaR and expected shortfall in portfolios of dependent credit risks: conceptual and practical insights. Journal of Banking \& Finance, 26(7), 1317-1334.

Hannan, E. J., \& Quinn, B. G. (1979). The determination of the order of an autoregression. Journal of the Royal Statistical Society. Series B (Methodological), 190-195. https://doi.org/10.1111/j.25176161.1979.tb01072.x

J Danielsson, JP Zigrand - Evidence from a Simple Equilibrium Model. London ..., 2003

Karanasos, M., \& Kim, J. (2003). Moments of the ARMA-EGARCH model. The Econometrics Journal, 6(1), 146-166. 


\section{INTERNATIONAL JOURNAL OF ENTREPRENEURIAL KNOWLEDGE}

Issue 9, volume 2, ISSN 2336-2960 (Online)

www.ijek.org

Katsiampa, P., 2017. Volatility estimation for Bitcoin: A comparison of GARCH models. Econ. Lett. 158, 3-6. https://doi.org/10.1016/j.econlet.2017.06.023

Këllezi, E., \& Gilli, M. (2000). Extreme value theory for tail-related risk measures (Vol. 3). FAME.

Klein, T., Thu, H. P., \& Walther, T. (2018). Bitcoin is not the New Gold-A comparison of volatility, correlation, and portfolio performance. International Review of Financial Analysis, 59, 105-116. https://doi.org/10.1016/j.irfa.2018.07.010

Liu, W., Semeyutin, A., Lau, C. K. M., \& Gozgor, G. (2020). Forecasting value-at-risk of cryptocurrencies with RiskMetrics type models. Research in International Business and Finance, 54, 101259.10.1016/j.ribaf.2020.101259

Manfredo, M. R., \& Leuthold, R. M. (1999). Value-at-risk analysis: A review and the potential for agricultural applications. Review of agricultural economics, 21(1), 99-111. https://doi.org/10.2307/1349974

Naimy V. and M. R. Hayek (2018). Modelling and predicting the Bitcoin volatility using GARCH models. International Journal of Mathematical Modelling and Numerical Optimisation 8(3):197.

Nelson, D. B. (1991). Conditional heteroskedasticity in asset returns: A new approach. Econometrica: Journal of the Econometric Society, 347-370. https:/ / doi.org/10.2307/2938260

Nieto, M. R., \& Ruiz, E. (2016). Frontiers in VaR forecasting and backtesting. International Journal of Forecasting, 32(2), 475-501. https://doi.org/10.1016/j.ijforecast.2015.08.003

Peng, Y., Albuquerque, P. H. M., de Sá, J. M. C., Padula, A. J. A., \& Montenegro, M. R. (2018). The best of two worlds: Forecasting high frequency volatility for cryptocurrencies and traditional currencies with Support Vector Regression. Expert Systems with Applications, 97, 177-192. https://doi.org/10.1016/j.eswa.2017.12.004

Peracchi, F., \& Tanase, A. V. (2008). On estimating the conditional expected shortfall. Applied Stochastic Models in Business and Industry, 24(5), 471-493.

Shahzad, S. J. H., Bouri, E., Roubaud, D., Kristoufek, L., \& Lucey, B. (2019). Is Bitcoin a better safehaven investment than gold and commodities? International Review of Financial Analysis, 63, $322-$ 330.

Stavroyiannis, S. and V. Babalos. (2017). Dynamic properties of the BitCoin and the US market. https://ssrn.com/abstract $=2966998$

Tan, Z., Huang, Y., \& Xiao, B. (2021). Value at risk and returns of cryptocurrencies before and after the crash: Long-run relations and fractional cointegration. Research in International Business and Finance, 56, 101347.10.1016/j.ribaf.2020.101347

Team, R. C. (2013). R: A language and environment for statistical computing.

Teker, D., \& Teker, S(2020). Estimation of Bitcoin Volatility: GARCH Implementation. International Journal of Economics and Management Studies (SSRG-IJEMS) - Volume 7 Issue 1 - Jan 2020

Tiwari, A. K., Kumar, S., \& Pathak, R. (2019a). Modelling the dynamics of Bitcoin and Litecoin: GARCH versus stochastic volatility models. Applied Economics, 51(37), 4073-4082. /doi/abs/10.1080/00036846.2019.1588951

Trucíos, C. (2019). Forecasting Bitcoin risk measures: A robust approach. International Journal of Forecasting, 35(3), 836-847 https://doi.org/10.1016/j.ijforecast.2019.01.003

Tsay, R. S. (2005). Analysis of financial time series (Vol. 543): John Wiley \& Sons.

Urquhart, A. (2016). The inefficiency of Bitcoin Economics Letters, 148, 80-82. https://doi.org/10.1016/j.econlet.2016.09.019

Yousaf, I., \& Ali, S. (2020). The COVID-19 outbreak and high frequency information transmission between major cryptocurrencies: Evidence from the VAR-DCC-GARCH approach. Borsa Istanbul Review, 20, S1-S10. 10.1016/j.bir.2020.10.003

\section{BRIEF DESCRIPTION OF AUTHOR/AUTHORS:}


INTERNATIONAL JOURNAL OF ENTREPRENEURIAL KNOWLEDGE

Issue 9, volume 2, ISSN 2336-2960 (Online)

www.ijek.org

\section{Cosmos Obeng}

ORCID ID: https:/ / orcid.org/0000-0003-1682-9270

Ph.D. Candidate, Tomas Bata University in Zlín, Faculty of Management and Economics, Mostní 5139, 76001, Zlín, Czech Republic

Email: obeng@utb.cz

Area of interest: Digital finance, Digital Contract, Financial risk management 